of removal of atoms must be known. It is the latter quantity that is the more difficult to measure. Two methods have been developed. One consists in actually measuring the decrease in the number of halogen molecules on illuminating the system, by an optical differential technique. The other consists in a proper examination of the expansion halogen vapour undergoes on illumination, that is, the Budde effect.

The behaviour of other reactive chemical entities such as $\mathrm{OH}, \mathrm{NH}_{2}, \mathrm{CH}_{3}, \mathrm{C}_{2} \mathrm{H}_{3}$, and so on, have been examined with similar but less refined methods, and there is here much work to be done before a complete correlation of all the data can be effected. For example, the life-time of these radicals can be determined by producing them photochemically and allowing their concentration to fall in the period of darkness succeeding illum. ination. Again, owing to the minute concentration, the chemical result in any one dark period cannot be measured. But by employing rotating sectors a large number of identical decay periods may easily be integrated to provide the information required.

The labelling of atoms in a molecule by using isotopes-radioactive and non-radioactive-has now assumed a familiar place in chemical laboratories. Deuterium is employed in all suspected cases of hydrogen atom lability and for acid-base catalysis, enolization, mutarotation and the like. Isotopic oxygen, though less plentiful, provides the key to debated mechanisms of hydrolysis and the constitution of bound oxygen atoms in molecules. Already nitrogen isotopes have indicated the rate at which nitrogen molecules are severed on synthetic ammonia catalysts. In fact, progress in this field is only limited by the rate at which isotopes may be produced, and the variety of reactions by the kinds of isotopes available.

In principle, radioactive indicators are used in the same way. They have the advantage of being easy to detect in small quantity, but often have practical limitations in their short life-times. This practical disability, however, can be overcome by using more powerful neutron generators. The question of the ionization of carbon-halogen bonds has been tackled in this way, and the biological applications of radio-phosphorus are becoming widely known.

Thus within a matter of a few years a new branch of physical chemistry has come into being. The principles of the subject are now well established, and it will not be long before every branch of chemistry will derive benefit from these advances in physico-chemical technique.

\title{
THE RELATIONSHIP BETWEEN PITHECANTHROPUS AND SINANTHROPUS
}

\author{
By Dr. G. H. R. von Koenigswald, Bandoeng, and Prof. Franz Weidenreich, \\ Peking Cenozoic Research Laboratory, Peiping Union Medical Collegge, Peking
}

$\mathrm{D}$ AVIDSON BLACK had remarked on the great similarity between the first skull of Sinanthropus to be found and the Pithecanthropus skull of Trinil, a condition which induced him to see in Pithecanthropus a Hominid form closely related to Sinanthropus (1931). The additional finds of the latter, unearthed in the interval, have confirmed Black's interpretation in every respect. But on the other hand, since the Pithecanthropus finds remained restricted to that rather incomplete specimen of Trinil, absolute evidence for his true Hominid character was lacking. In such circumstances, there was no other way open but to await the discovery of additional Pithecanthropus material before definitely solving this problem.

These discoveries materialized. Following the recovery of a rather primitive infantile skull (Homo modjokertensis) in 1936 and of a lower jaw of an adult individual, one of us (G. H. R. von K.), during 1937, discovered a skull in the undoubted Trinil deposits of Sangiran. This skull, preserved up to the basal region, conforms in every respect as to size, shape, and details to Dubois's Trinil specimen. Dubois, however, opposed the attribu. tion of this skull to Pithecanthropus. Nevertheless, the details of the interior, as well as exterior surfaces of the skull, and also the skiagrams, delineating the otherwise indistinct sutures and breakage lines, show not the slightest trace of irregularity or deformation, such as would be unavoidable if the assembly of the fragments had been artificially adapted to a particular form. To this skull of Sangiran was added another skull fragment derived from the same deposits and of the same site during the summer of 1938, briefly described in Nature of October 15, 1938, p. 715, by us. We are now in a position to report on an additional Pithecanthropus find made this year. It concerns the lower part of an upper jaw of unusually large dimensions, comprising the processus alveolares of both sides with completely preserved nasal floor and palate, the complete left 
dental arch with all the teeth leading from the canine backward, and a part of the right dental arch up to the first molar. The incisors were lost, but their alveoli are preserved (see accompanying reproductions, $a$ and $c$ ). Afterwards the skull belonging to this jaw was also found. It comprises the posterior third of the brain case, including the entire basis.

Morphologically and geologically, we believe we are justified in attributing all these finds to Pithecanthropus. This type is thus represented by the following finds :

(1) Skull of Trinil (Dubois, 1891): Pithecanthropus skull $\mathrm{I}$.

(2) Mandible of Kedung Brubus (Dubois, 1891): Pithecanthropus mandible A.

(3) Juvenile skull of Homo modjokertensis (Geol. Survey 1936)*.
Of the Sinanthropus cranial material, skulls $\mathrm{E}$ and II of Locus $\mathrm{L}$ are most suitable for a comparison, having capacities of approximately 915 c.c. and 1015 c.c., respectively. These skulls are slightly larger than the Pithecanthropus skulls, but they are the same in general form and particularly in height.

The main differences so far as the skull cap is concerned consist in that in Pithecanthropus (skulls I and II) the supraorbital tori pass directly over to the extraordinarily flattened forehead, whereas in Sinanthropus the supraorbital ridges are much more demarcated from the tuber-like vaulted but otherwise also strongly receding forehead. On the other hand, the obelion region in Sinanthropus is flat, while in Pithecanthropus it is rounded off. The greatest sinilarity is seen in the general form and structure of the temporal

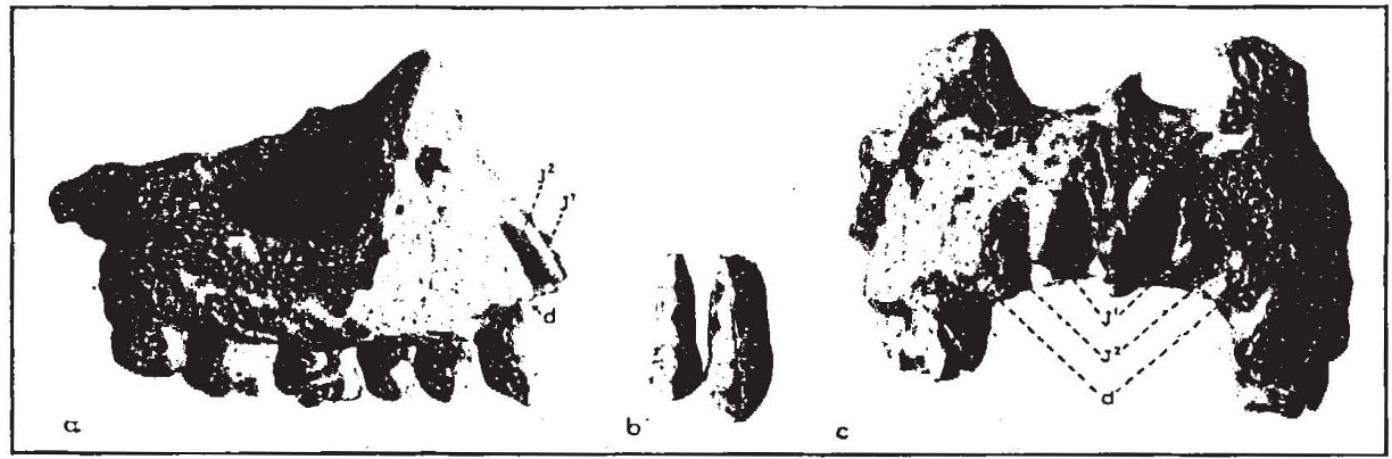

(a) Upper jaw of a male Pithecanturopus (Sangiran, January 1939), viewed from the right side $d$, Diastfisa; $J^{1}$, alveolus of $J^{1} ; J^{2}$, Alveolus of $J^{2}$. $\frac{2}{3}$ Nat. Size.

(b) Upper right caNine aNd first premolar of a male individual of SiNaNthropui (FIV), so as TO DEMONSTRATE THE PROTRUSION OF THe CANINE. $\frac{2}{3}$ NAT. SIZE.

(c) The same as $(a)$ but viewed from IN FroNt. $\frac{2}{3}$ NAT SIzE.

(4) Mandible of Sangiran (v. Koenigswald, 1936): Pithecanthropus mandible B.

(5) Skull of Sangiran (v. Koenigswald, 1937): Pithecanthropus skull II.

(6) Skull fragment of Sangiran (v. Koenigswald, 1938) : Pithecanthropus skull III.

(7) (a) Maxilla of Sangiran (v. Koenigswald, 1939) ; (b) Skull fragment of Sangiran (v. Koenigswald, 1939) : Pithecanthropus skull IV.

The Sangiran skull (Pithecanthropus skull II) resembles the Trinil skull as closely as one egg another. The former (skull II) is only slightly smaller than skull I-its capacity being 835 c.c. as compared with 914 c.c. of the Trinil skull-but its parictal and occipital parts are relatively broader. The Sangiran fragment (Pithecanthropus skull III) is, in its preserved part, not so flat as the other two (skulls I and II), but otherwise resembles them in every detail. In addition, it bears a distinctly pronounced crista sagittalis.

* On the basis of my study of the original, I have now come to the conclusion that this infantile skull really represents a Pithecanthropu child. I shall report on this clsewhere.-F.W. and occipital bones, and there is absolute conformity in some special details of these bones. The Pithecanthropus fragment III and Sinanthropus skull $\mathrm{E}$ show identical features even in apparently unessential structures. Beside the first mentioned sagittal crest, there is in the obelion region on each side of the sagittal suture a short groove which Black described and illustrated in Sinanthropus skull E.

With regard to the lower jaws, that from Kedung Brubus is characterized as representing Pithecanthropus by the exclusively basal location of a broad digastric fossa-the only usable criterion. This mandible corresponds in size and proportions to the small female Sinanthropus jaws $\mathrm{A}$ and $\mathrm{H}$, and the mandible II II, more recently discovered, and not yet described. The jaw from Sangiran (Pithecanthropus mandible B), on the other hand, is large, and corresponds to the large male Sinanthropus jaws G I and $K I$, with the exception that the frontal section is considerably thicker than in the latter. 
The upper jaw from Sangiran (see reproductions) has as yet nothing comparable among the Sinanthropus specimens, for the two upper jaw fragments of the latter known up to the present have much smaller dimensions and proportions, implying that they belong to female individuals, while the upper jaw from Sangiran must be ascribed to a male.

The differences in size and proportions of the upper and lower jaws of both Pithecanthropus and Sinanthropus, apparently chiefly due to sexual differences, also serve as a criterion of the cranial conditions in this respect. The lower and upper jaws from Sangiran are much too large for the small Pithecanthropus skulls I and II, whereas the lower jaw fragment of Kedung Brubus would seem to fit them better. It may be concluded, therefore, that the two Pithecanthropus skulls, regardless of their minor differences in size and thickness, must have belonged to female individuals, whereas the rather heavy Pithecanthropus skull IV represents undoubtedly an old male individual.

With respect to the dentition, the Pithecanthropus molars are larger than those of Sinanthropus available so far. But the lower incisorsso far as the size of the crowns can be estimated from that of the alveoli-and especially the lower canines of Pithecanthropus, are decidedly smaller than those of Sinanthropus. The canines of the Pithecanthropus upper jaw (see reproduction $a$ ) protrude considerably beyond the premolars, despite the fact that both are much worn. They conform in this respect to the Sinanthropus canines (see $b$ ) so far as male individuals are concerned. The pattern of the Pithecanthropus canine resembles that of Sinanthropus, but is less complicated by lacking the cingulum so characteristic of the latter. These differences are also true for the premolars and molars, in so far as no one of these teeth in Pithccanthropus shows such primitive characteristics as are found in Sinanthropus. Pithecanthropus, therefore, undoubtedly stands in this respect at the upper limit of the range of variation approaching the Neanderthal types. On the other hand, in respect to other features, Pithecanthropus is of a more primitive nature than Sinanthropus : for example, the second molar of both upper and lower jaw of Pithecanthropus is distinctly larger than the first, and the third lower molar the longest of all three. In addition, it is evident that-the first example of a fossil Hominid known hitherto-the upper canines of both sides are separated from the lateral incisors by a broad diastema, the width of which amounts to $6.2 \mathrm{~mm}$. on the right side $(d$, in reproductions $a$ and $c$ ). This width comes close to the average width known for male gorillas and corresponds to that of the male orang (average width, according to Remane, $6.8 \mathrm{~mm}$. and $6.2 \mathrm{~mm}$. respectively).
The dental arch of the Pithecanthropus upper jaw is long and relatively narrow. The front teeth, according to the alveoli, were ranged within a curved line and directed forward, whereas the molars form two straight and backwardly diverging rows. Thus, all the skeletal remains and teeth of Pithecanthropus and Sinanthropus so far available prove the close general relationship between the two types.

With respect to the affinity of the Pithecanthropus femora-that is to say, the so-called Trinil femur, and the five femora afterwards recovered by Dubois and also attributed to Pithecanthropusit must be taken into consideration that the seven femora of Sinanthropus, most of them represented only by shafts, show significant differences when compared with those femora. All of the Sinanthropus femora display, among other characteristics, a marked degree of platymeria, and at the same time a very low pilaster index; while the supposed Pithecanthropus femora show no indication of this kind, and are in all respects identical with those of modern man. All this points against the probability of their belonging to Pithecanthropus.

Pithecanthropus and Sinanthropus undoubtedly represent the most primitive Hominid forms known hitherto, which, according to Boule, may be ranged collectively under the name Prehominids. Which of the two types must be taken as the more primitive cannot be decided with absolute certainty for the present. Fragments of Sinanthropus skulls suggest that this type includes also specimens the capacities of which did not exceed that of Pithecan. thropus II-as, for example, Sinanthropus skull $J$ -and, on the other hand, those with a very long and rather low cranium, as the Sinanthropus skull fragment $\mathrm{H}$ III. Nevertheless, it is certain that Pithecanthropus shows some significant characteristics which must be considered more primitive than those evident in Sinanthropus, especially the presence of a diastema in the upper jaw.

Considered from the general point of view of human evolution, Pithecanthropus and Sinanthropus, the two representatives of the Prehominid stage, are related to each other in the same way as two different races of present mankind, which may also display certain variations in the degree of their advancement.

The Prehominids are separated from the Neanderthal group by a considerable gap. On the other hand, an apparently close relationship exists between Pithecanthropus and Homo soloensis, the skulls of the latter appearing like an enlarged form of the former. Certain peculiarities of Pithecanthropus reappear in exactly the same form in Homo soloensis. Those traits which suggest an already more advanced type, like the 
greater cranial capacity, and several other structural features, can be derived directly from Pithecanthropus, and correspond to the condition in the Neanderthal stage already attained by Homo soloensis. The two available fragments of the tibia of Homo soloensis show no special peculiarities, with the exception of a pronounced platymeria, exhibiting only recent human characters in their general form and in details.

The finds reported herein show that Java has become the most important centre for the study of Prehominid forms. Not only Prehominids, but also the following evolutionary stage, Homo soloensis, are represented there. Furthermore, we know that the Wadjak man of Java represents another early form of recent man, whose upper jaw (Wadjak II) displays in some respects a most surprising resemblance to the Pithecanthropus upper jaw.

In conclusion, we wish to express our gratitude to the officers of the Government of the Netherlands East Indies, and the Carnegie Institution in Washington for their generous support, which made possible not only the more recent investigations in Java itself, but also our joint study, conducted in the Cenozoic Research Laboratory, Peiping Union Medical College, Peking, of recently obtained Pithecanthropus material.

\section{A NATIONAL ATLAS OF BRITAIN}

\section{By Prof. E. G. R. TAylor, Birkbeck College, London}

$\mathrm{P}$ ROPOSALS for a National Atlas of Great Britain and Northern Ireland were first put forward from Section E (Geography) of the British Association at the Cambridge meeting in 1938. They met with a warm response from several other sections, with the result that a representative committee got to work and was able to present a preliminary plan for the Atlas in the form of a report to the Association at its Dundee meeting, which has been already noticed in NATURE*. Just before the break-up of the meeting, a joint discussion of the report by interested sections took place, and it is here proposed to outline the ideas concerning the Atlas which emerged during this discussion. As will presently appear, many problems still await solution, but these can fruitfully be examined during the period in which more active steps must wait upon the national emergency.

Put in the briefest possible terms, a National Atlas aims at the cartographical representation of the physical circumstances of the national territory (such as surface configuration, structure, hydrology, mineral deposits, animal life and plant cover), side by side with the circumstances of human occupancy (such as land use, fisheries, mining and industrial enterprises, lines of communication, distribution of population, of occupations, of boundaries, of amenities). Neither physical nor human phenomena are static, and many presentday distributions bear the imprint of the past. Hence the plan necessarily embraces a certain number of historical maps, and even pre-historical, such, for example, as the map of Roman Britain, and the map of Pleistocene Glaciation.

- NATCRe, 144, 702 (1939).
While the term 'National' as used in the title carries in the first instance the obvious meaning that the maps are limited to national territory, it possesses also a secondary but very important significance. A National Atlas, if it is to justify publication, must be national in its appeal and in its use. The selection of material and the choice of cartographical technique must be made with the intelligent citizen as well as the scientific investigator in mind. 'This does not imply a so. called 'popular' style of presentation, for fortunately the last twenty-five years have seen a great advance in the general appreciation of maps. At one time only the gazetteer type, limited to the expression of location, was understood. To this was later added the map showing local con. ditions: the topographical map, or the daily weather map. More recently still, as may be observed from the appearance of examples in the daily press, distribution maps, usually statistically based and limited to a single phenomenon, have become acceptable; such, for example, are maps of agricultural output, of population density, or of ethnic elements. In brief, the language of the map has become a familiar one.

It is well to remark, however, that Government departments lag far behind the general public in this respect. The enormous volumes of statistics which they collect are rarely, if ever, illuminated by being plotted in map form. Indeed, they are often summarized and tabulated in ways that obscure geographical facts of great significance. It is, in fact, true of statisticians and economists as a body that, up to the present, they have neglected or even rejected the use of maps, and it will be very regrettable if their co-operation is 